This preprint copy is an accepted manuscript of the paper published in RiDE in 2009. Please cite as:

Dawson, E., Hill, A., Barlow, J. and Weitkamp, E. (2009). Genetic testing in a drama and discussion workshop: Exploring knowledge construction. Research in Drama Education 14(3): 361-390

http://www.tandfonline.com/doi/abs/10.1080/13569780903072174

\title{
Genetic testing in a drama and discussion workshop: Exploring knowledge construction
}

\section{Emily Dawson, Anne Hill, John Barlow, Emma Weitkamp}

\begin{abstract}
In this pilot project, drama was used to situate genetic testing in a social and cultural context - that of the family. The drama was used to stimulate discussion about social issues relating to genetic testing, such as who has the right to know the results of the test and whether participants would want to know their 'genetic future'. A 10-minute, openended drama was developed as stimulus for a further 40-minute discussion-based workshop that focused on the issues that someone considering having a genetic test might face. The drama was performed to groups of 20-60 secondary school students. These larger groups were broken down into groups of four to 10 for the discussion aspect of the workshop. Seven drama workshops were delivered to 16-19-year-olds in Bristol, Reading and Southampton. A total of 240 students participated in the workshops. The project found that the drama discussion workshop format prompted students to develop their learning about the social issues surrounding genetic testing, with an increase in comprehension and scientifically appropriate use of language and concepts over the course of the workshop. The project also found students learned socially, as a group, using the discussion time to develop their arguments and scaffold knowledge with their peers on to that delivered in the workshop.
\end{abstract}


Keywords: drama workshops; genetic testing; social learning; secondary education

\section{Introduction}

This pilot project sought to explore the potential of drama-based workshops as a tool for stimulating discussion and debate about emerging scientific issues amongst young people (aged 16-19). A drama-based approach was chosen because it allowed the social and ethical context surrounding genetic testing to be presented and for different characters' perspectives to be explored. In this exploratory project a short, open-ended drama (approximately 10 minutes) was used to situate issues relating to genetic testing in a family context. Following the short drama, students were involved in small-group (four to 10 students) discussion led by a trained facilitator and using a common framework of questions for discussion. The focus of the drama was on a test for early onset dementia and this was placed in a context where various family members experienced direct health and care implications either now or in the future. The project investigated how participants in the workshop developed their understanding of genetic testing and particularly the related social and ethical issues during the workshop with a view to investigating the potential of this approach as a tool to facilitate learning.

\section{Making meaning about science}

The need to engage people with what scientific advances might mean for them formed the starting point for exploratory research into the use of dramatic narrative and discussion as a tool for exploring how 16 19-year-olds perceive and learn about the social issues surrounding biomedical advances. Social constructivist learning theories are used to analyse the student engagement with the drama and subsequent discussion in this exploratory research. Social constructivist learning theories in this context refer to contemporary learning theories, based around the work of Vygotsky and added to by Wertsch (1998) and Lave and Wenger (1991) amongst others. It constitutes learning as a constructed, communicative, social activity, embedding learners in a cultural and historical context, influenced by and influencing their community. 
Even when still in formal education, the layperson constructs ideas about science by combining knowledge gained in an educational setting with bits and pieces of scientific traditions, personal experience and hearsay. People come to visualise new scientific concepts by relating them to familiar concepts; thus Moscovici (2000) argues that social representations of science facilitate changes in knowledge and understanding. Dialogue with others is an important aspect of the construction of common social representations of science as well as a means of constructing individual understanding. It 'forms the fertile background in, and against which, everyday knowledge in the form of social representations is subjected to a continuous process of formation and transformation' (Wagner and Hayes 2005, 219). Wagner (2007) links the concept of 'vernacular' language to the social construction of scientific knowledge. He argues, for example, that in the early stages of social acceptance of new scientific research, there is a need for useful metaphors to facilitate communication.

Scientific knowledge may be one such focus for everyday discussions. Wagner suggests five main sources of motivation for everyday interest in and discussion of science and technology: the need to be able to use everyday but quite complex appliances such as an iPod or computer, a natural interest in the field of science and technology, a need to be informed about scientific and technological innovations, the need to acquire and display such knowledge because it holds 'symbolic power' and in order to use knowledge about science and technology within everyday conversation, that is, in order to have something to say when science-related issues and topics arise. Duveen argues that 'knowledge arises from human passions and as such is never disinterested: rather it is the product of particular groups of people who find themselves in specific circumstances in which they engage in definite projects' $(2000,2)$. In other words, most people do not acquire new knowledge for the sake of discovering truth, but rather as a means of coping with their own needs. This notion that there is a purpose to knowledge acquisition suggests the importance of context in learning. It is not just the 'what', but the 'why' that must be addressed for knowledge to be internalised.

\section{Engaging young people through drama}


One means of communicating the 'why' is to contextualise scientific knowledge by placing it in a familiar context. Live drama or theatre provide one such medium through which scientific information and ideas can be contextualised. Theatre with a scientific focus has become well known, from works raising questions about the motivations of scientists, such as Galilleo's Finger by Bertholt Brecht or Michael Frayn's Copenhagen, to pieces to engage young people with current social issues surrounding science, such as Judith Johnson's Starfish or any of the range of dramatic performances undertaken in science museums designed to bring exhibitions to life (see, for example, Magni 2002 for a discussion of the different types of science theatre and the Wellcome Trust Pulse 
projects for further examples ). Theatre and drama are recognised as effective tools for 
engaging children and young people with science (see, for example, McNaugton 2006; Ødegaard 2004) and drama has been widely used to add a personal dimension to social and scientific issues, such as health (see, for example, Jackson 1993; Starkey and Orme 2003; Deeny et al. 2001; McDonald and Nehammer 2003; Dalrymple 2006). This personal dimension is akin to the social context that Wagner and Hayes (2005) argue is essential for the construction of knowledge.

Previous studies have found that drama used in education is particularly suited for engendering sympathy and empathy and providing a meaningful context in which to explore research ideas (McNaughton 2004; Jackson and Leahy 2005). Drama builds on students' past experiences, enriching these experiences through identification with new fictional situations and characters. It is not disinterested or abstract, but firmly situates an issue in a particular dramatic context. This context provides a hook to engage students with an issue, something which Duveen (2000) suggests is essential for learning. Cooper (2004) argues that theatre is an ideal way to create the social learning environments which Vygotsky suggested were essential for development. Drama also offers the opportunity to pose 'what if' questions and to explore opinions on controversial topics from the perspectives of different characters. This ability to present multiple perspectives on an issue was a key reason why this project used drama.

It has been argued that 'live' performance helps stimulate debate and discussion because it provides access to fictionalised narratives. Thus, 'a play becomes a catalyst which educators can use to provoke students to assess critically and to debate the viability and desirability of moral choices that are offered by dramatic characters outside the work itself, within the social and cultural contexts of existential reality' (Basourakos 1999, 480). The use of engaging characters helps students to empathise with the problems and dilemmas faced by these characters, providing an emotional connection to what otherwise might seem abstract. Drama may also stimulate the reflective practice that Kolb (1984) believes to be a key element of the learning process. Drama is known to stimulate empathy and emotional connection to certain characters in the performance. It is likely that through this empathy, these participants will undergo some change themselves. 
Drama has more effect on the audience than many other forms of communication because it tells an engaging story, it affects the audience emotionally, and it depicts changes in characters with whom the audience identifies...The empathic emotional response in the audience is the motivational force that induces members of the audience to reconceptualise the central problem depicted in the drama and resolve it in a similar manner in their own lives. (Kincaid 2002, 150) Similarly, Day (2002) found that while students' moral reasoning during the drama workshop was limited, after the workshop, when students had had time to reflect, they realised the complexity and conflicts of moral issues presented using drama.

The purpose of the drama used in this project was to stimulate discussion and for this reason no concluding or resolution scene was created. Gesser-Edelsberg, Guttman, and Isrealashvili (2006) found that closed-ended dramas can stifle discussion by creating a sense that the action is inevitable. This can be compounded if the audience fails to identify with the characters. Gesser-Edelsberg, Guttman, and Isrealash- vili argue that educational dramas should be designed to allow the audience to access the questions and alternatives faced by the characters to help them evaluate options and develop decisionmaking skills. Evaluation of the Meet the Gene Machine project which also used a drama workshop format found that participants engaged fully with the discussion and particularly enjoyed the aspects which were not closely linked to the science curriculum (GraphicScience 2005). They felt the drama had caused them to think about the ethical issues raised by the drama.

\section{Genetic testing in the workshop}

Many new developments in science, such as genetic technologies, have the potential for both positive and negative impacts at individual and societal levels. Parott et al. (2004, 118) note that 'numerous messages around genes and health are working their way into the lay public's spheres of influence'. These are issues that students will encounter throughout their lives and which students may come into contact with personally. Dewhurst (1992) argues that students should encounter moral dilemmas during school in order to help prepare them for the decisions and judgements they will need to make 
throughout their adult lives, while Jallinoja and Aro (2000) suggest that interventions are needed that allow citizens to discuss the potential social and ethical issues that arise with developments in genetic testing.

The drama, used as a stimulus in this project, framed the issue in the context of predictive genetic testing with the grandparent being the affected family member. The disease chosen, early onset Alzheimer's disease (EOAD), is an autosomal dominant genetic disease, which means that if you have the gene for the disease you will develop the disease at some point in the future. This is the same as diseases such as Huntingdon's disease, but is not typical of most genetic diseases which may be recessive, such as cystic fibrosis, or disorders involving more than one gene, such as diabetes.

Predictive testing for genetic diseases is now available for some single gene disorders, such as Huntingdon's disease. Predictive testing is carried out before a person shows symptoms of a disease, and in some cases can be carried out prenatally through the use of prenatal genetic diagnosis. In the case of an autosomal dominant disease as used in this drama, this type of testing yields either a favourable (the person does not carry the disease-causing gene and will not develop the disease) or unfavourable (the person carries the disease-causing gene and will develop the disease) results. Yaniv, Benador, and Sagi $(2004,317)$ studied participants' willingness to undergo predictive genetic testing and found that people 'often prefer not to know, as if they are choosing “protective ignorance', '. Similarly, a survey of people at risk of Huntingdon's disease carried out at around the time a genetic test became available, showed that $50 \quad 80 \%$ of respondents indicated an interest in predictive testing (Kessler et al. 1987). However, only around $15 \%$ of at-risk people actually applied for testing (Decruyenaere et al. 1995). In the case of Huntingdon's disease, and the fictitious scenario used in the drama workshops reported here, a person with one affected parent (that is one parent with the disease) would have a 50\% chance of developing the disease. If, as in our scenario, a grandparent has the disease, then the individual's risk is reduced to $25 \%$. Undergoing testing in this latter situation, however, has implications for other family members (i.e. the parent in the intervening generation) because an unfavourable result for the individual 
would mean an unfavourable result for their parent. This immediately raises questions about who within the family should have (or has a right to) access to the results of the genetic test (particularly if unfavourable) and the impact that this information might have on family relationships.

Framing the drama around the choice of whether or not to undergo genetic testing for a late onset genetic disease introduced both an immediate dilemma for the main character and allowed us to explore issues around the role of the family in the decision-making process. It also allowed us to address issues around who should have the right to access your genetic information. We were particularly interested to explore the ways that young people discussed these issues and used their own knowledge and background to build an understanding of the complex nature of the subject and whether a subject such as predictive genetic testing presented using an emotional narrative would help participants move from a black and white understanding of the issues to a more nuanced understanding.

\section{Methods}

\section{Research objectives}

The aim of this research was to investigate the learning processes that took place during a drama and discussion workshop about the social implications of genetic testing. The project involved creating and implementing a series of workshops for 16 19-year-olds in formal education that sought to engage students with issues around genetic testing. Content and process research was carried out to investigate how students responded to these workshops. The research into meaning making in the workshops can be broken down into 'what' meaning was made and 'how' this meaning was made. This paper will focus on 'how' students made meaning from the workshop and what learning processes took place.

The epistemological and ontological approach taken was essentially a socialconstructivist one, without taking this to an extreme relativist position (Guba and Lincoln 1994). The research therefore is based on the premise that learning, both the procedures 
involved and the knowledge gained, is a constructed, social and relative process (see, for example, Falk, Moussouri, and Coulson 1998; Lave and Wenger 1991). The phenomenon under investigation was the learning involved in the workshops, which were developed through a piloting process and evaluated and improved throughout the project. The workshops were designed to act as both interesting educational sessions for students and as a vehicle through which to carry out research into how students made meaning when participating in discussion. The research design focused on techniques that explore how such learning processes take place, with recorded small-group discussion at the core of the research, supported by mindmaps and observations. The recorded discussions aimed to demonstrate if, and in what ways, students built upon each other's knowledge and experiences, along with the workshop content delivered through the drama (Kitzinger 1994). The mindmaps completed by students before the workshop and again after the discussion were designed to illustrate whether students had gained knowledge, relative to their earlier mindmap comments, through the course of the workshop (Falk, Moussouri, and Coulson 1998). The observations provided a general picture of the levels of engagement in the workshops and were used to improve the workshop structure, while the questionnaires provided brief background information on individual students.

\section{The workshop format}

The social implications of genetic testing were initially conveyed through a 10-minute open-ended drama, selected for its ability to provoke debate and to engage the student audience. This was followed by a 30 40-minute small-group (four to 10 participants) discussion which enabled both 'what' the students thought about these issues and to an extent 'how' they thought them to be captured for analysis. Each discussion group was led by a trained facilitator. During the workshop students were asked to complete a mindmap (filled in at the start of the workshop, before the drama, and at the end of the workshop) and a questionnaire (following the drama but before the discussion). It should be noted that, in line with approaches such as Augusto Boal's Forum Theatre, the drama and subsequent workshop did not seek to provide factual information about genetic testing (though the scientific content provided was accurate), but rather to stimulate discussion and encourage students to think about the social implications (both personal 
and for the family as a whole) of genetic testing. The sessions were, therefore focused on stimulating questions and discussion rather than providing answers.

\section{Key elements of the workshop: science, drama and discussion}

\section{Science}

Initial subject pre-testing with a group of 110 students, between 16 and 19 years old, found the relatively rare EOAD to be unfamiliar to many pupils who also stated that lack of familiarity was a strength for this topic. EOAD was therefore chosen from a range of potential subjects related to genetic testing issues (other subjects tested included breast cancer, saviour siblings, cystic fibrosis and addictive behaviour). Breast cancer, for example, was felt to be gender-specific and not of interest to the male students. Cystic fibrosis was viewed as too familiar and something which they had encountered in school previously. Regarding addictive behaviour, students felt the notion that this might be genetically determined was far fetched. The science content of the drama discussion workshop was placed in a family social context to allow participants to explore what genetic testing for EOAD might mean for the different family members.

\section{Drama}

Six performers were recruited from the third-year BA Performance course at Southampton Solent University. It was felt that trained actors would improve the dramatic potential of the performance. The actors developed the drama by improvising around a script and the story was left open ended in order to provide the audience with questions rather than answers, to provoke discussion (see scenes 1 and 2 below).

\section{Scene 1}

This scene takes place in a family home over Sunday lunch. The Mother is in the kitchen preparing the meal, her father (referred to as 'the grandfather'), her son (Josh) and his girlfriend (Emily) are in the dining room. The grandfather has Early Onset Alzheimer's Disease and is being in turn both forgetful and abusive. The aunt arrives for dinner and spends time trying to tell the mother to put her father in a home, which the mother passionately refuses to do. There is a great deal of tension in this scene, brought to a head 
when the grandfather hurls his glass across the room in the middle of the dinner whilst shouting. At this point Josh storms out of the room followed by Emily. They have an argument about whether Josh should have a genetic test as he is very worried he will have the same illness as his grandfather. Emily cannot see the point in doing it.

\section{Scene 2}

Josh and Emily are waiting at the doctor's surgery, continuing their argument from the previous scene about whether or not Josh should have a genetic test. Josh goes in to see the doctor and the doctor explains that Early Onset Alzheimer's Disease (the disease which Josh's grandfather has) can be inherited. A test is available for this disease, but Josh needs to consider the implications this test may have for him and his family. The doctor then informs Josh that if his test shows he has the inherited the illness, it will mean his mother must have inherited the same gene from her father in order to have passed it on to him. Josh agrees that the situation is complicated and that it is a decision that he will have to think about. The scene ends leaving Josh's decision about whether or not to have a genetic test unmade.

Small-group discussions (four to 10 students) took place following the drama; these were recorded for research purposes to explore the way students interacted during the discussion and the content discussed. The facilitators included three members of the research team and the six performers, who were given training and practice in discussion facilitation and moderation as part of their role in the research project. Facilitators were trained in focus-group moderation methods, for example, recognising body language and asking open-ended ques- tions (Morgan 1998). Small-group discussions, akin to focus groups, were used as they provide an opportunity to investigate people's views on a specific subject and create a space for the group to develop a better understanding of the subject under discussion.

Focus groups are typically used to provide rich, qualitative data in a manner that mimics normal conversation (Morgan 1998). While it has become apparent that their precise subject focus removes them from the sphere of 'normal' conversation (Warr 2005; Green 
and Hart 1999), they have been used by social researchers to examine both specific topics and changes in the behaviour of participants (Kitzinger 1994; Morgan 1998). It has been noted that groups of people rarely engage in a serious discussion on a specific subject (Gamson 1992) yet during focus groups people discuss a subject, argue and re-examine their views, and through such interactions develop their understanding of a topic (Warr 2005). Small-group discussions provided a means of exploring the underlying research premise that gathering knowledge or learning is a social and constructed process (see, for example, Lave and Wenger 1991; Falk, Moussouri, and Coulson 1998). The small group discussions were designed to follow the themes in the drama and facilitators each had questions to guide them through the discussions (see List 3).

The small-group discussions therefore present an opportunity to research both the views of students on the subject of the social implications of genetic testing and to examine the processes by which participants come to their opinions. This allowed exploration of the effects of interactions between people on their understanding of the issues in a specific workshop designed for formal education. It also allowed preliminary investigation into the ways participants engaged with the content provided by the drama and by their peers during discussion. Analysing these interactions provides insights into the ways

\section{List A. Facilitator guide for small-group discussions}

- . Do you think Josh should have a genetic test? Please vote and show me red for no and green for yes.

- What other reasons might there be to have a genetic test? What if there is more information on Josh's genetic test than just results about EOAD? Should he be told by the doctor about any other diseases that show up?

- What are the implications for Josh if he has the test? Think back to the argument between Josh and his girlfriend in the play.

- What are the implications for Josh's aunt? What are the implications for Josh's girlfriend? What are the implications for Josh's children?

- What about the implications for Josh's mum if he does have the 
test? Does she deserve to know about his results?

- . Why do you think Josh's mum should know the results of Josh's genetic test?

- . Is there anyone else in his family you think Josh should tell about his results?

- Do you think Josh should tell his girlfriend about his results? Why?

- . Is there anyone else who should have access to Josh's test results? What about his university, his bank, his insurance company? Why?

- . Thinking about the drama and the discussion, let's have one last vote; do you think 'Josh' should have a genetic test?

- . Talk through who has changed their minds or if they haven't if you have time. participants developed their own knowledge and understanding of a subject both individually and as a group (Waterton and Wynne 1999).

\section{Research methods and data collection}

The research was conducted over the course of seven workshops and included four sixth form General Studies groups, one Drama BTEC group, one GCSE Science group and a group of Drama undergraduates. All workshops took place in southern England. Multiple approaches to data collection were employed around a core method of recorded smallgroup discussions, supported by mindmap exercises. A total of 240 students participated in the workshops of which 140 were female and 99 were male (one participant declined to specify their gender). The small-group discussions carried out in the workshops were recorded using cassette recorders and hemispherical microphones.

Mindmaps were used to collect data before the workshop and after the discussion. The mindmap exercise was based on the research methods used by Falk to evaluate learning in museum settings (Falk, Moussouri, and Coulson 1998) and enabled the information students brought to the workshop to be contrasted with participants' understanding after their workshop experience. This allowed some assessment of individual changes in 
responses to the question posed. Students were given blue pens and five minutes to fill in the mindmaps before the drama began and another five minutes with a red pen following the small-group discussion. A total of 239 mindmaps were completed.

\section{Analysis}

\section{Discussion analysis}

Where possible all the small-group discussions were recorded, resulting in 36 group discussions. All recordings were listened to and identified for transcription using two techniques: sound quality and data saturation. Recordings were initially rejected on the basis that the sound quality was too poor for transcription (Myers 2000). Two recordings were then selected for transcription from each of the seven workshops.

Following a period of familiarisation with the recordings and transcripts, the data were reviewed for literal themes around genetic testing decision making. Interpretive themes were then drawn from the discussions and reflexively examined by the primary researcher and two others on the research team (Meyrick 2006). This approach was chosen to allow the maximum amount of information to be gleaned from the available data (Mason 2002). Through this process of qualitative analysis a coding framework was developed by the research team and used by the primary researcher to index the transcripts systematically (Ritchie and Spencer 1994). After the initial 14 transcripts were coded, they were examined for data saturation in the code frames agreed by the research team, and a further 10 recordings were transcribed and coded using the coding framework (Bowen 2008). Nvivo was used to manage and code the discussion data.

\section{Mindmap analysis}

Mindmaps were employed for their ability to assess potential learning as a result of the workshop. The mindmaps were analysed across two dimensions, changes in quantity of responses and changes in the content of responses. The first examined the difference between what was initially noted on the mindmap and the second set of comments on the mindmaps. This was analysed in terms of the number of branches drawn with comments and the number of words in these comments. The mindmaps were then analysed for their thematic content. Using a literal content analysis, the different themes that emerged from 
the data were counted and grouped from most to least frequent (Mason 2002; Falk, Moussouri, and Coulson 1998). The mindmaps provided insight into the number of different themes students identified and the level of detail with which they were able to express themselves. Analysis also sought to explore changes in the number of appropriate responses (e.g. responses related to genetic testing) as opposed to inappropriate responses (such as 'orange juice').

\section{Results}

\section{Discussion group data}

The discussion data illustrate how students developed their understanding of the themes presented in the drama from simple, often one-sided views, to more sophisticated opinions, informed by the different sides of the debate. These processes worked together to result in knowledge exchange, to complicate the issue for the students and to build towards a sophisti- cated, nuanced understanding of the issues involved. The themes from the discussion data are illustrated with examples from the transcripts. Transcript examples are referred to by workshop number (e.g. W1, W2) and discussion group number (e.g. G1, G2). Workshop numbers were allocated in the order in which the workshops were conducted. Group numbers were allocated to each facilitator and applied consistently to all workshops. Thus W1 G1 and W2 G1 were facilitated by the same person.

In the quoted section, students are identified by the code S1, S2 etc. In a number of cases it was difficult to identify students unambiguously throughout the course of the entire transcript. To avoid improperly ascribing comments to specific students and for ease of reading, it was decided to label each quoted excerpt independently. In some cases more than one excerpt is quoted from a group. In each such case, numbering is from S1 onwards and it should not be assumed that the student labelled S1 is the same person in each quoted excerpt.

\section{Character perspective and individual perspectives}


The students used the characters presented in the drama as a way into talking about the issues thrown up by the family illness situation. When talking, students took on board the personalities of different characters from the drama to varying degrees. Students ranged from those who spoke and argued as though they were the character, to those who were able to differentiate clearly between what they would do and what they thought the character should do. This effect was most pronounced with the lead character (Josh) when students discussed whether he should decide to have a genetic test.

Some students took on the identity of the character 'Josh' when discussing the decisions he faced and personalised the issues, talking about the question of what 'Josh' should do in the first person.

S1: I would take it to put my mind at rest, I'd rather know than not know. (W1 G1)

S1: If I found out there was a possibility I could have it, then I'd want to know for sure cos then I could try and get everything that I wanted to do before then done. (W7 G9)

S1: If I had Alzheimer's and I couldn't look after myself, I wouldn't wanna live like that and you could take steps to get you, know, um, and you know, like and, all the insurance and everything, if you knew it would affect your life even if you had another 20 years of good health, you wouldn't be able to get a mortgage, do you know what I mean. (W3 G3)

There were also students who were able to distinguish between themselves and Josh and describe appropriate behaviour for Josh and different behaviour for themselves.

S1: If he wants to then fair enough but I personally don't think he should, I wouldn't. (W3 G6)

S1: If he wants to then obviously fair enough but I personally wouldn't just because if you do find out then you're going to worry the whole of your life when it's going to happen . . . and I think things happen for a reason and I think there's no point worrying about it until it comes to it, so there's 
no point worrying about it, ... happen anyway, so even if he does find out then it's up to him but he's still going to be worrying about it, he's still going to like... I personally wouldn't because I

wouldn't want to worry about it until it actually happens. (W3 G6)

S1: It depends what sort of personality you've got, he sort of seemed quite unsure and it would make him feel better if he knew but if he didn't want to know then ... otherwise you would do different things in life that you might otherwise not done. (W1 G2)

S1: If he's truly worried about it,and . . concern [of him] then he needs to go and tackle it head on ... get tested for it, if he really feel that it's not going to be a worry, I mean, none of us feel like it's a worry at the moment that's why none of us . . . get tested, so, if it's one of those things where you feel like you've got something wrong with you. (W6 G4)

\section{Personal examples}

A number of students used personal, often tragic stories from their own lives or their families to justify their views on the different issues being discussed. These family examples were used as powerful pieces of evidence for the students' arguments and were taken seriously by the groups involved. The first examples illustrate students building on their own experiences to explore and explain how they feel about having a genetic test.

S1: But then I know that [me and my sister are] going to get breast cancer . .. it's kind of obvious in my family, the stuff that's happened . . . but it doesn't really bother me, if I get it I get it, if I don't I don't, I don't really care, I wouldn't go and have a test done.

S2: But . . like say your sister was diagnosed with [a disease] would you want to get, knowing that it's common in your DNA, genetically ... wouldn't you want to go and be tested.

S1: Not really, no. 
S3: If you want to go and get tested you just know it would be a worry, if you know it's in your family, it's in your genes then you'd think 'ok there's a possibility that I might get this'.

$\mathrm{S} 1$ : I think you're just more aware of it. (W6 G4)

S1: Um, my uncle died, he had early onset Alzheimer's . . . and I think really you should do, because my uncle just had the same and everyone's got to go sometime, it's just, yeah. (W3 G3)

In the following extract, the final student identifies a practical reason (treatment, although the treatment she proposes is not related to sickle cell anaemia) for having a genetic test. In the scenario presented in the drama, no treatment was available. In a number of discussions, students highlighted the possibility of treatment or behaviour change to reduce the risk of disease (e.g. drinking less and eating healthy foods were identified as strategies for people at risk of heart disease) as possible reasons to have a genetic test.

S1: Sickle cell ...

Facilitator: So do you think it would be good to be, have genetic testing for susceptibility to that?

S1: . . that's where you get that when you're born, my mum done that to me when I was born.

$\mathrm{S} 2: \ldots$

I: Do you think it's good to know though?

S2: Uhum (affirmative).

S1: Yeah it is.

S2: Cos people can give you like high sugar. (W7 G3)

In another example, two students use personal stories to argue against each other. The first personal story was followed with a personal counter story: both students using their experiences of family illness to illustrate conflicting arguments in the group discussion. 
S1: My uncle, when he was born, he was born with a weak heart and he was told that he wouldn't see his 20th birthday, but my grandparents decided not to tell him . . . my uncle is now 40 and he's still alive, so they reckon it was the fact that they didn't tell him, basically put no pressure on his mind or body, so that's why I'm saying no, I think it would risk the rest of his life ... and he wouldn't be able to live it in full...

$\mathrm{S} 2$ : But then at the same time, my mum suffers from multiple sclerosis and she got diagnosed at 36 and her brother that she hasn't seen since she was 7, he lives in New York, and now she'd never going to get round to doing it, cos she hasn't got the strength to do it, and if she'd of known that she was going to have it, 10 years ago she would have gone. (W3 G7)

\section{Scaffolding}

Students developed a more sophisticated understanding of genetic testing arguments through their discussions by building on previous comments or stories. They modified their views or changed their minds during these discussions, which led to a more rounded understanding of the situation. The first example below shows a student using her personal experiences as a mother to explain why she felt it was important for the mother character in the drama to be involved in the decision-making process, and the other students incorporated this into their own arguments.

I: Why do you think Josh's mum should have the right to know . . ?

S1: Cos she's the mother and I'm a mother, I know . . .

S2: Without his permission.

S1: Yeah, yes, I wouldn't need permission from my son to.

S2: Yeah but this guy seems to be over 18 . .

$\mathrm{S} 1$ : Then again that's down to Josh to tell me, I mean if I'm going with him

[if I know] the problem if I [pick] up the symptoms and I probably would

[have gone] with him and I would be worrying about him and then he would talk to me if we are close enough but then again we might not be close enough and he might ... tell me, he's. . . 
S2: It depends on the situation they're in I think cos.

S1: Yeah.

S2: Depends on what sort of situation you're in, because like to me if he didn't want his mum to know, if he didn't want her to know so it doesn't make his mum worried but then no, but then again if you're saying that, if she actually went with him and someone that actually knows about the problem and he's asking her help then I think yeah. (W3 G6)

In this example, students build on the assertion of rights made by the first student. Through the discussion, both student 1 and student 2 move toward agreement, with student 1 acknowledging the son's right to privacy and student 2 realising that the decision might depend on the situation and relationship between the two individuals involved.

EOAD is an autosomal dominant disease, so for 'Josh' to inherit the appropriate gene, it must have come from one of his parents, who will also be affected by the illness. In the example below, students build on each other's understanding of genetic inheritance and opinions about who should be informed to re-evaluate their views on the disclosure of genetic test results.

S1: It's not going to like affect her hugely, like, it's something to do with him do you know what I mean.

S2: But surely it will because yeah.

S3: She will have it.

S1: I keep forgetting that, she's got it as well. (W6 G8)

A third example shows a group changing their minds about the benefits of talking to a counsellor. The recording started before the discussion and while talking amongst themselves the students ridiculed the idea of talking to a counsellor, during the facilitated discussion the same students began to talk about a counsellor in a much broader, more positive way. 
S1: Would you tell your doctor?

S2: Yeah yeah, definitely.

S3: Yeah but wouldn't they know? It'd be on there. S4: Yeah but if you changed doctors, it might not be.

S2: Basically it's health people init, you might need to tell a counsellor as well, if it affects you mental health as well, before you get it, you might need to speak to a counsellor about it so they can help you.

S1: Yeah a counsellor.

S2: So a counsellor might be able to help you with it, just help you mentally cope with it, cos that's the place where you're weakest. S2: True. (W7 G7)

In another group, students explored the implications for the girlfriend of Josh having a genetic disease. In doing so, they drew on the mother's situation in the drama to consider what it would be like for the girlfriend if Josh developed EOAD.

I: Does anyone remember that scene? With Josh and his girlfriend, in the kitchen? What were they talking about?

S1: How he can't deal with the fact of what's going on and she was just like.

S2: How his mother's getting tired.

I: So what implications can you think about for Josh and his relationship with his girlfriend? If he has the test, what does that mean for him and his girlfriend?

S1: If they have kids, they might have it.

S3: Like how you just said that he's sad cos his mum's looking after his granddad.

S2: Oh yeah the doctor said his mum ...

S1: She'll have to look after him.

I: Or he's going to have to maybe look after his mum? 
S3: Ah she'll get stressed out.

I: Or his girlfriend might have to look after him. S1: That'd be a bit shit for her. (W7 G1)

Similarly, participants built on their understanding of genetic inheritance to explore the implications of having a genetic disease in the family for future generations. This group discussed whether knowing you are going to develop a genetic disease in the future and could pass it on to your children would influence whether you would have children, although clearly other factors would also come into play such as whether prenatal genetic testing could be carried out. Here we particularly see participant 2 (S2) developing a more sophisticated understanding of the implications of having a genetic disease in your family.

I: If he has children, do you think it is fair, is it fair to have children if he knows he has it?

S1: Yeah, if that's a part of what he wants to do. As long as he tells them he's got it.

S2: Oh you mean like, if he knows his children might have it.

I: Yeah, he could pass it to his children.

S2: Oh he could pass it to his children.

S1: You wouldn't stop having kids just because you're ill, if you could and you wanted kids

S3: You might want kids, you might not.

S1: Exactly.

S3: But if he's going to pass it on to them, then he does risk the kids life, so...

S2: Yeah and he better know about it. (W3 G7)

\section{Use of scientific concepts}

Within the discussions students often employed terms that could be considered scientifically inaccurate to convey their meaning about genetics. For example, students 
related genes and inheritance to 'blood'. It should be noted that the workshops were not intended to bridge a knowledge gap and therefore facilitators did not provide additional information or correct students during the conversations unless to redirect the direction of the conversation or when participants asked for clarification. The reason students were not 'corrected' was to allow the researchers to explore the extent to which the students could use the drama stimulus and their existing knowledge to build their under- standing of the science and issues raised. It should be noted, though, that students were provided with factually correct background information on EOAD, genetics and genetic testing at the end of the workshop. There was variation in how the students talked about the genetic concepts presented in the workshop, with some students reflecting ideas about genetic inheritance with accuracy and humour.

S1: So you have the gene inside you.

S2: But it doesn't necessarily take effect. (W3 G3)

S1: But would they be able to tell? Like, at 20?

I: With genetic testing, yeah.

S1: Oh.

I: Yeah.

S2: It's in your genes, not these ones you wear the ones in your body. (W6 G9)

Other student groups built on initial misunderstandings and talked about classroom examples of genetic diseases.

I: What other genetic diseases do you know about? S1: Aids.

I: That's not a genetic disease.

S1: So isn't it like things that can be passed on?

I: Well it's got to be passed on genetically. S2: Sickle cell.

S1: Thalassaemia.

I: Good, sickle cell as well, yep. 
S1: Oh and that other one with the blood.

I: Haemophilia, very good.

S3: What's that?

S1: When you bleed, you can't stop bleeding. I: So when you get a cut, you bleed.

$\mathrm{S} 1$ : It's called the royal disease.

S4: The royal disease, didn't we learn it in science. S2: Yeah. That's what you learn in science. (W7 G1)

There were also a number of examples of the use of vernacular language to express scientific concepts, both accurately and inaccurately.

S1: Um, ... does she come from the same blood line. (W4 G6)

S2: If you want to go and get tested you just know it would be a worry, if you know it's in your family, it's in your genes then you'd think 'ok there's a possibility that I might get this'. (W6 G4)

Vernacular language was also used as a means of scaffolding knowledge by the groups as illustrated (incorrectly) by this group, where students talk about the disease as being in the blood stream and about diseases skipping generations. The discussion starts out with the use of 'blood stream' as a metaphor for genetic inheritance. However, this more general metaphor for inherited diseases triggers the idea of diseases skipping generations. While this is certainly true for some genetic disorders it was not the case for the disease presented in the drama, which as the doctor character explains is an autosomal dominant disease (i.e. if you have the gene you will get the disease). These students, therefore, use scaffolding to move away from the simple autosomal dominant scenario presented in the drama to a far more complex situation involving uncertainty over the likelihood of developing the disease (which is also by far the more common situation with genetic disorders). 
S1: It's more likely that she will get it if Josh has got the disease as well in his blood stream then it's ... and her father has got it.

$\mathrm{S} 2: \ldots$

S1: Well yeah it's going to be passed down but it can skip generations. S3:

Yeah exactly ...

S2: ...genes.

S1: .. .going to get the disease, but it can, if you do have, you know it can skip so it might make her think 'oh I'm getting it' and then she might think she's getting symptoms and then. (W6 G4)

\section{From black and white to grey}

At the end of the discussions students developed a more sophisticated and nuanced understanding of the position of the characters in the drama, their own opinions and the general social issues surrounding genetic testing technologies. In the following example students arrive at the conclusion that different people make different decisions and that the decision to have a genetic test and disclosure are complicated, personal and individual.

S1: It just depends, some people would take the news differently to others, some people would think yes this is a great chance for me to . . to do stuff that I really love, with other people would just sort of hide away. (W1 G2) Although the group in the excerpt below does not achieve consensus, there is a dialogue and sharing of ideas that shows an understanding of the complexity of the issues surrounding genetic testing.

S1: You were saying that, genetic testing you can then find out if you've got it and then find a cure for it, I think if we use genetic testing just to find out if he'd got the disease I think that's more I don't know ethical than if, $\mathrm{S} 2$ : then if you start curing then you're going just mess everything up, are you going to become a. .

S3: . . but if we use genetic testing to find out if we've got diseases, we won't stop there, humans as people just won't stop there. 
S1: I think it gives people a choice . . . it doesn't keep people in the dark, I mean at the end of the day you're not forced to // have.

S4: Technology allows you to know something.

$\mathrm{S} 1$ : . . at the end of the day it's the individual's choice, if someone doesn't agree with it fair enough, they don't have to have a genetic test. (W5 G3)

In discussing the implications of having a genetic test for the main character, Josh, the group below considers how this information would affect how he lived his life. As the three excerpts show, the students decide that the issue is complex and one which individuals would deal with in different ways.

S1: He's going to live his life in fear, he will be constantly looking over his shoulder, won't he?

S2: I don't know, it might make him try and live every day to the full and make him try and.

S1: Depends on the person, doesn't it? How they deal with the situation.

S3: Yeah but you could get knocked down by a car next week.

S1: Yeah but people don't take that attitude do they, you've got to, it's got to depend on the individual when deciding these things, you can't decide en masse can you.

$\cdots$

S1: You can't decide for the whole of society ...

S2: Everyone has their different outlooks.

S3: Yeah people deal with problems differently. (W6 G4)

\section{Mindmap data}

The mindmaps clearly show students had engaged with the learning process of the workshop and were better able to draw on this experience when completing their mindmaps for the second time. Additionally, the mindmap data revealed what themes the students were linking to the question 'what dilemmas are involved in genetic testing?' 
The differences in the 'before and 'after' data from the mindmaps varies from student to student, with an overall trend for students to write more and longer entries at the end of the workshop than at the start. The mean increase in the number of entries across the sample was 1.8, while the mean increase for the number of words across the sample was 19.2. This increase in both the number of entries and words shows students responses to the mindmap question increased after taking part in the workshop.

The content analysis results show that both themes and vocabulary are more appropriate to the question 'what dilemmas are involved in genetic testing?' after the workshop compared with themes and vocabulary used initially (see Figure 1). Examining the quantity of appropriate concepts used provides insight into whether the students were picking up on the relevant messages in the workshop, or other elements of their experiences to address the mindmap question. An analysis of the change in themes listed before and after the workshop shows a shift toward greater understanding of the issues raised by the workshop.

[Figure 1]

The themes that arose most in the initial mindmap exercise were 'nothing' (57 of 239), supplemented with the additional categories of 'don't know' (23 of 239) and 'what is it' (11 of 239). The next most frequent category of response was coded as 'other' (37 of 239), and included all responses conceptually inappropriate in terms of the mindmap question and workshop, i.e. 'orange juice'. After this conceptually appropriate concepts appear, such as 'ethics' (30 of 239) and 'problems' (33 of 239). However, an intraindividual comparison of detail and vocabulary used in these initial mindmaps shows less detail and less sophisticated vocabulary than responses from the same individuals after the workshop.

The second mindmap exercise at the end of the workshop contained more appropriate themes, described in more detail with appropriate vocabulary. The most popular themes in the second exercise were around family, like 'family implications' (140 of 240) and 'family disclosure' (74 of 239). Other disclosure issues were also found in the post- 
workshop mindmaps, such as 'who should know' (81 of 239) and 'knowing your future' (123 of 240). These issues reflect those which were addressed in the drama and discussion sections of the workshop, highlighting student engagement with the ideas presented and discussed and an increased awareness of the social implications surrounding genetic testing.

\section{Discussion}

The research has allowed insight into how students made meaning in this particular series of drama and discussion workshops. The facilitated discussion following the drama prompt provided students with an opportunity to explore and exchange ideas. As suggested by Vygotsky (see Wood, Bruner, and Ross 1976), we found evidence that social interaction played a role in shifting students' understanding of the issues at stake, through the use of discussion as a tool for scaffolding knowledge. Students used the discussion to make sense of the drama workshop in a number of ways. For example, discussion between students involved meaning making through group negotiation and reflection, when students discussed whether to disclose genetic information to a counsellor. These students explored alternative actions amongst themselves, reflecting on the options and finally choosing a course of action, demonstrating Wertsch's notion of teleological action.

In making meaning, students drew on their own personal experience in making arguments and explaining their points of view. Two students in one group, for example, constructed narratives about their own family experiences of disease. They drew on these experiences to help construct and understand the new situation and information presented in the drama. These students were weaving new information into existing narratives which Wertsch (1998) suggests is an important aspect of reflection, integration and learning. In the group discussion, these narratives were juxtaposed to convey different points of view, and ultimately meaning (if not agreement) was negotiated between the students. 
Personal perspectives were combined with vernacular science language, as Moscovici (2000) suggests, to relate new concepts and issues presented in the drama to the familiar and personal. This connection to the personal was illustrated by the many references to personal and familial experience relating to genetic inheritance or health themes raised throughout the groups. Participants also drew on the combined experience and knowledge of the group to construct their ideas about genetic testing.

Within the discussions students often employed terms that could be considered scientifically inaccurate to convey their meaning about genetic testing. This use of everyday language to describe a new area of science has been previously identified by Wagner (2007) and Wagner and Hayes (2005) regarding genetically modified food. Wagner links what he has termed 'vernacular' language to a social need for useful communicative metaphors at the early stages of social acceptance of scientific research. This idea can be applied to the way that students discussed the issues raised during the workshops. Although many of the vernacular terms used may be considered scientifically inaccurate it was encouraging that the mindmap data showed an increase in the number of conceptually appropriate categories listed after the workshop compared with entries at the start of the workshop. While many of these categories might be considered social rather than scientific, it clearly demonstrates the potential of this type of engagement activity as a tool for building meaning about scientific concepts and in particular the social implications of such technologies.

As suggested by Kincaid (2002), it was clear that participants in the drama and discussion workshops were able to relate to the dilemmas faced by the central characters. They related these to their own personal experiences, using their experiences as a means of rephrasing one of the central problems posed by the drama whether to have a genetic test. As Basourakos (1999) argues, we found that the drama provided a catalyst for discussion and debate about rights and a starting point from which participants could develop their under- standing of the complex social and ethical issues surrounding genetic testing. The results of this pilot project suggest that drama and discussion workshops are an appropriate way to stimulate discussion and learning about the social 
issues surrounding science. The approach could usefully be applied to a wide range of scientific areas, from stem cells and novel health care technologies to more speculative ideas such as human enhancement. Issues currently facing society today, such as health care funding, would also be amenable to this approach.

Students engaged with the drama in a variety of ways, with some students taking on the identity of the characters during the discussion and personalising the dilemmas they faced while others maintained some emotional distance from the characters, distinguishing between the actions they thought the characters' ought to take and the decisions they thought they would make in similar circumstances. This transfer between students' own lived realities and events in the drama was also evident through the use of personal stories as a means of justifying opinions and adding weight to arguments. This research supports Cooper's (2004) argument that theatre can be used to stimulate socially mediated learning. The findings suggest that this style of workshop is particularly conducive to knowledge exchange, sharing personal experiences, opinions, building on the views of others and developing, as a group, a more rounded and complex view of a situation than was held previously by those involved.

The drama workshop was structured with a view to promoting reflection as well as meaning making through discussion. Kolb (1984) highlights the importance of inner reflection and tools employed throughout the workshop, such as the mindmap exercises, were designed to allow time for individual reflection on the workshop experience.

Discussion questions were also phrased to prompt reflection on specific issues, such as disclosure and rights to access to genetic information. Time constraints of fitting in with the school day meant that these opportunities for reflection were somewhat limited and there was no opportunity to capture longitudinal data that might offer insights on whether students reflected on this experience at a later time.

\section{Further research}

Longitudinal studies would provide an insight into the longer-term impacts of this type of intervention on students' understanding of the ethical dilemmas associated with some 
new scientific developments as well as providing an insight into whether drama helps engender longer-term engagement with science and accompanying social issues. The longer-term impact of 'one off' interventions, such as this is likely to be limited, and more complex models of engagement involving repeat interventions (such as a series of drama workshops covering a range of scientific issues) would be interesting to explore. Similarly, it would be interesting to explore this approach to science education using different styles of theatre to investigate the effect of theatre style on learning and engagement.

\section{Acknowledgements}

The authors would like to thank the anonymous reviewers for their helpful comments. This project was supported by the Wellcome Trust through the People Award Scheme, grant no. WTO77832MA. Note 1. Seehttp://www.wellcome.ac.uk/Funding/Publicengagement/Past-funding /WTX035068.htm.

\section{Notes on contributors}

Emily Dawson is a research associate in the Science Communication Unit at the University of the West of England, Bristol. Her interests focus on how people engage with science communication initiatives, specifically the ways in which participants in events and activities make meaning.

Anne Hill is a Principle Lecturer at Southampton Solent University. Anne's research interests lie in the cultural communication area, with a current focus on the influence of culture on the reception of health messages. She is a co-author (with James Watson) of A Dictionary of Media and Communication Studies (2003).

John Barlow is a Principle Lecturer at Southampton Solent University where he runs the BA Performance course. John has a background in theatre, television and film, with extensive experience of creative origination and production of single films and stage productions.

Emma Weitkamp is a Senior Lecturer in Science Communication at the University of the West of England, Bristol. Her research interests focus on the use of narrative as a tool for 
communicating science and the role of emotion as a trigger for engagement. She is also interested in the ways that participants use narrative to construct meaning about an issue.

\section{References}

Basourakos, J. 1999. Moral voices and moral choices: Canadian drama and moral pedagogy. Journal of Moral Education 28: 473-89.

Bowen, G.A. 2008. Naturalistic inquiry and the saturation concept: A research note. Qualitative Research 8: 137-52.

Cooper, C. 2004. A struggle well worth having: The uses of theatre-in- education (TIE) for learning. Support for Learning 19, no. 2: 81-7.

Dalrymple, L. 2006. Has it made a difference? Understanding and measuring the impact of applied theatre with young people in the South African context. Research in Drama Education 11: 201-18.

Day, L. 2002. Putting yourself in other people's shoes: The use of Forum theatre to explore refugee and homeless issues in schools. Journal of Moral Education 31, no. 1: 2134.

Decruyenaere, M., G. Evers-Kiebooms, A. Boogaerts, J.J. Cassiman, T. Cloostermans, K. Demyttenaere, R. Dom, J.P. Fryns, and H. Van Den Berghe. 1995. Predictive testing for Huntingdon's disease: Risk perception, reasons for testing and psychological profile of test applicants. Genetic Counseling 6: 1-13.

Deeny, P., A. Johnson, J. Boore, C. Leyden, and E. McCaughan. 2001. Drama as an experiential technique in learning how to cope with dying patients and their families. Teaching in Higher Education 6: 99-112. 
Dewhurst, D.W. 1992. The teaching of controversial issues. The Journal of Philosophy of Education 26: 153-63.

Duveen, G. 2000. Introduction: The power of ideas. In Social representations: explorations in social psychology, ed. S. Moscovici, 1-17. Cambridge: Polity Press.

Falk, J.H., T. Moussouri, and D. Coulson. 1998. The effects of visitors' agendas on museum learning. Curator 41, no. 2: 106-20.

Gamson, W. 1992. Talking politics. Cambridge: Cambridge University Press. GesserEdelsberg, A., N. Guttman, and M. Isrealashvili. 2006. Educational drama and the dilemma of 'false-catharsis': Lessons for theory and practice from a study of anti-drug plays in Israel. Research in Drama Education 11:

293-311.

GraphicScience. 2005. Meet the mighty gene machine: Evaluation report. http:// www.scu.uwe.ac.uk/Files/mgm_evaluation_report.pdf (accessed January 2008).

Green, J., and L. Hart. 1999. The impact of context on data. In Developing focus groups research: Politics, theory and practice, ed. R.S. Barbour and J. Kitzinger, 21-35. London: Sage.

Guba, E.G., and Y.S. Lincoln. 1994. Competing paradigms in qualitative research. In Handbook of qualitative research, ed. N. Denzin and Y.S. Lincoln, 163-88. London: Sage.

Jackson, A., and H.R. Leahy. 2005. Seeing it for real - authenticity, seeing and learning in museums. Research in Drama Education 10: 303-25.

Jackson, T. 1993. Learning through theatre. London and New York: Routledge. Jallinoja, 
P., and A.R. Aro. 2000. Does knowledge make a difference? The association between knowledge about genes and attitudes toward gene tests. Journal of Health Communication 5: 29-39.

Kessler, S., T. Field, L. Worth, and H. Mosbarger. 1987. Attitudes of persons at risk for Huntingdon's disease toward predictive testing. American Journal of Medical Genetics 26: 25-70.

Kincaid, D.L. 2002. Drama, emotion and cultural convergence. Communication Theory 12: 136-52.

Kitzinger, J. 1994. The methodology of focus groups: The importance of interaction between research participants. Sociology of Health and Illness 16: 103-21.

Kolb, D. 1984. Experiential learning: Experience as the source of learning and development. Upper Saddle River, NJ: Prentice-Hall.

Lave, J., and E. Wenger. 1991. Situated learning: Legitimate peripheral participation. Cambridge: Cambridge University Press.

Magni, F.E. 2002. Theatrical communic-action of science. Journal of Communication 1: 1-14.

Mason, J. 2002. Qualitative researching. London: Sage. McDonald, G., and S. Nehammer. 2003. An evaluation of a drug education play for schools in south Wales. Health Education 103, no. 2: 83-7.

McNaughton, M.J. 2004. Educational drama in the teaching of education for sustainability. Environmental Education Research 10: 139-55. 
McNaughton, M.J. 2006. Learning from participants' responses in educational drama in the teaching of education for sustainable development. Research in Drama Education 11: $19-41$.

Meyrick, J. 2006. What is good qualitative research? Journal of Health Psychology 11: 799-808.

Morgan, D.L. 1998. The focus group handbook. London: Sage.

Moscovici, S. 2000. Social representations: Explorations in social psychology. Cambridge: Polity Press.

Myers, G. 2000. Analysis of conversation and talk. In Qualitative researching with text, image and sound. A practical handbook, ed. M.W. Bauer and G. Gaskell, 191-206. London: Sage.

Ødegaard, M. 2004. Gen-Gangere: A science-in-drama project about knowledge, biotechnology and Ibsen's dramatic works. School Science Review 86, no. 315: 87-94.

Parott, R., K. Silk, J. Weiner, C. Condit, T. Harris, and J. Bernhardt. 2004. Deriving lay models of uncertainty about genes' role in illness causation to guide communication about human genetics. Journal of Communication 54: 105-22.

Ritchie, J., and Spencer, L. 1994. Qualitative data analysis for applied policy research. In Analyzing qualitative data, ed. A. Bryman and R. Burgess, 173-94. London: Routledge.

Starkey, F., and J. Orme. 2001. Evaluation of a primary school drug drama project: Methodological issues and key findings. Health Education Research 16: 609-22. 
Wagner, W. 2007. Vernacular science knowledge: Its role in everyday life communication. Public Understanding of Science 16: 7-22.

Wagner, W., and N. Hayes. 2005. Everyday discourse and common sense: The theory of social representations. Basingstoke, UK: Palgrave.

Warr, D.J. 2005. 'It was fun . . . but we don't usually talk about these things': Analyzing sociable interaction in focus groups. Qualitative Inquiry 11: 200-25.

Waterton, C., and B. Wynne. 1999. Can focus groups access community views? In Developing focus group research: Politics, theory and practice, ed. J.S. Barbour and J. Kitzinger. London: Sage.

Wertsch, J.V. 1998. Mind in action. Oxford: Oxford University Press.

Wood, D., J.C. Bruner, and G. Ross. 1976. The role of tutoring in problem solving. Journal of Child Psychology and Psychiatry 17: 89-100.

Yaniv, I., D. Benador, and M. Sagi. 2004. On not wanting to know and not wanting to inform others: Choices regarding predictive genetic testing. Risk Decision and Policy 9: $317-36$. 